\title{
Damping-off caused by Pythium aphanidermatum on sugar beet in Egypt
}

\author{
Mohamed Abdellatif A. Mahmoud ${ }^{1}$ (D) . Ayman Faisal Omar ${ }^{2} \cdot$ Ayman A. A. Mohamed $^{3} \cdot$ Moustafa I. Gouda $^{4}$. \\ Amero A. Emeran²
}

Received: 11 August 2020 / Accepted: 24 August 2021 / Published online: 13 September 2021

(c) Australasian Plant Pathology Society Inc. 2021

\begin{abstract}
Damping-off, root rot and necrotic lesions were observed on sugar beet (Beta vulgaris) seedlings in the Kafrelsheikh Governorate, in the northern part of the Nile River delta, Egypt. Pythium aphanidermatum was identified as the causal agent using the morphology of the asexual and sexual morphs and molecular studies. This is the first record of $P$. aphanidermatum on sugar beet in Egypt.
\end{abstract}

Keywords Pythium aphanidermatum - Sugar beet · Damping off

The Kafrelsheikh Governorate, in the northern part of the Nile delta region, is the center of production of sugar beet (Beta vulgaris) in Egypt. In the summer of 2016, sugar beet growers throughout the region were complaining that sugar beet seedlings were dying rapidly. In most cases, infected plants germinated and emerged, but within 5 days approximately $20 \%$ became stunted. Typically, their roots become water-soaked, grey-black lesions developed on the hypocotyls of germinated seedlings, and in some cases leaves wilted and died. The healthy sugar beet seedlings (Fig. 1a), infected seedlings ultimately collapsed and died (Fig. 1b-c).

Isolates of the causal agent were generated by excising approx. $5 \mathrm{~mm}$ long segments of the root at the boundaries between healthy and diseased tissue. The segments were surface-sterilized by washing with tap water for $5 \mathrm{~min}$, dipping in $0.5 \%$ sodium hypochlorite for $1 \mathrm{~min}$, then immersing in sterile water for 2-3 min. The sterilized root pieces were placed on sterile filter paper to dry and plated on potato

Mohamed Abdellatif A. Mahmoud

mohamed2020sugarbeet@gmail.com

1 Faculty of Agriculture, Kafrelsheikh University, Kafrelsheikh, Egypt

2 Department of Agriculture Botany, Faculty of Agriculture, Kafrelsheikh University, Kafrelsheikh, Egypt

3 Department of Agriculture Agronomy, Faculty of Agriculture, Kafrelsheikh University, Kafrelsheikh, Egypt

$4 \quad$ Plant Pathology Research Institute, Agricultural Research Center (A.R.C), Giza, Egypt dextrose agar medium (PDA) being before incubated at $25 \pm 3{ }^{\circ} \mathrm{C}$ in the dark for 3 day. Single hyphal tip isolates were generated and four representatives were stored in sterile water under the accession numbers EPCRS65, EPCRS66, EPCRS67, EPCRS68 in the Egyptian Phytomicrobial Collection for Research Sustainability (EPCRS)Excellence Center Department of Agricultural Botany, Faculty of Agriculture, Kafrelsheikh University, Kafrelsheikh, Egypt.

The purified isolates were grown on cornmeal agar (CMA) in the dark at $30{ }^{\circ} \mathrm{C}$ for 10 days and were then examined microscopically to determine their morphology under light microscope at $\times 400$. The keys of van der Plaats-Niterink (1981) were used to assist in the identification of the isolates. The colonies of all four isolates were white, covering the entire agar surface with aseptate, hyaline hyphae $4.8 \pm 1.3 \mu \mathrm{m}$ in diam. The oogonia were terminal, smooth, globose and $23 \pm 1.5 \mu \mathrm{m}$ in diam (Fig. 1f-2) each with a single aplerotic oospore, $17 \pm 1.9 \mu \mathrm{m}$ in diam. Antheridia, usually one per oogonium, were intercalary or terminal, broadly sac-shaped and $12 \pm 1.8 \mu \mathrm{m}$ wide (Fig. 1f-1). Sporangia were developed from the terminal complex of swollen hyphae (Muthukumar 2010). The isolates were compared with descriptions of Pythium species (Gherbawy, et al. 2005) and most closely matched that of $P$. aphanidermatum.

The identity of the Pythium isolates was confirmed by PCR and sequence analysis. Genomic DNA was extracted from the mycelium of each isolate grown on CMA for $10 \mathrm{~d}$, using a modified protocol of Guo et al. (2000). The ITS region of rDNA of the four isolates (PyBv-1, PyBv-2, 


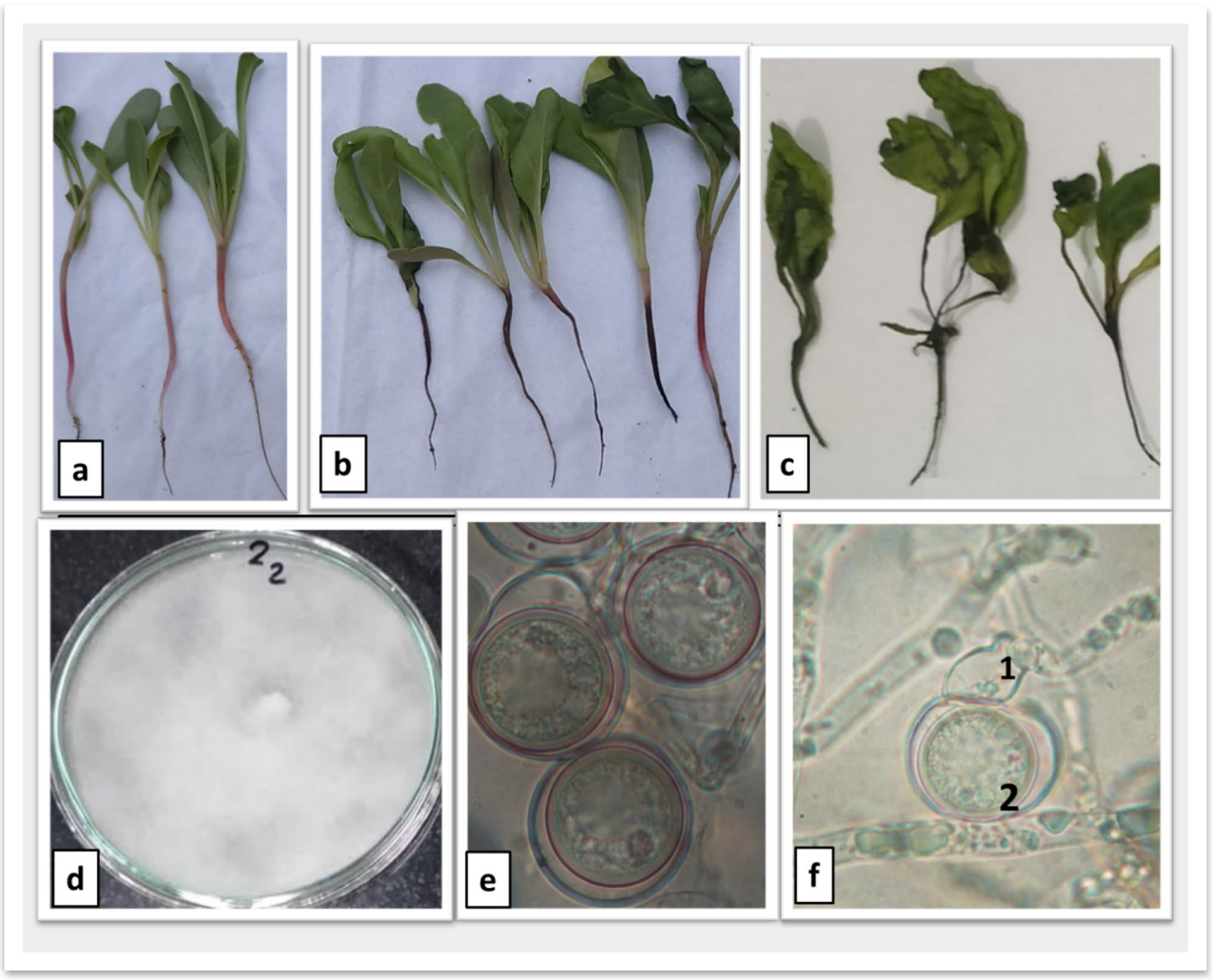

Fig. 1 a Healthy sugar beet seedlings. b Early damping-off symptoms. c Dying leaves on infected seedlings. d A colony of $P$. aphanidermatum on potato dextrose agar medium. e Free oogonia. f-1 Antheridium. f-2 Oogonium

PyBv-3 and PyBv-5) were amplified using the primers ITS1/ITS4, sequenced and deposited in the GenBank databases under accession numbers of SAMN1 1042134, SAMN11042131, SAMN11042132 and SAMN11042133, respectively. The phylogenetic tree showed that the four Egyptian isolates formed a single clade with seven isolates of Pythium aphanidermatum from other countries, with 100\% homology (Fig. 2).

Pathogenicity tests on sugar beet seedlings were conducted using the four isolates of $P$. aphanidermatum. Inoculum was prepared by transferring six plugs $(5 \mathrm{~mm}$ diameter) of each isolate from 3-day-old cultures growing on CMA to a sterile cornmeal-sand medium. The medium (11.2 $\mathrm{ml}$ of cornmeal, $200 \mathrm{ml}$ of sand, and $80 \mathrm{ml}$ of deionized water) was prepared by autoclaving it in $500 \mathrm{ml}$ flasks for $40 \mathrm{~min}$, on successive days. The isolates were allowed to colonize the cornmeal medium for 10 days in the dark at $25{ }^{\circ} \mathrm{C}$. The flasks were shaken every second day to ensure the uniform colonization of the medium.

A soil mix consisting of the field soil(clay), sand, and peat moss (3:1:1 by volume) was moistened and autoclaved for $1 \mathrm{~h}$ on each of two consecutive days (Brantner and Windels 1998). Five hundred (500) g of the sterile potting mix was placed into $13-\mathrm{cm}$-diam. plastic pots which had been lined with paper towel. For each isolate, $10 \mathrm{~g}$ of the colonised cornmeal sand medium was mixed through the entire potting mix in four pots, and another four pots with uninoculated potting mix were used as controls. Then, 10 seeds of the sugar beet var. Kwamera were sown in each pot. All pots were placed in a controlled environment greenhouse at $32 / 24{ }^{\circ} \mathrm{C}$ day/night and with a $12 \mathrm{~h}$ 


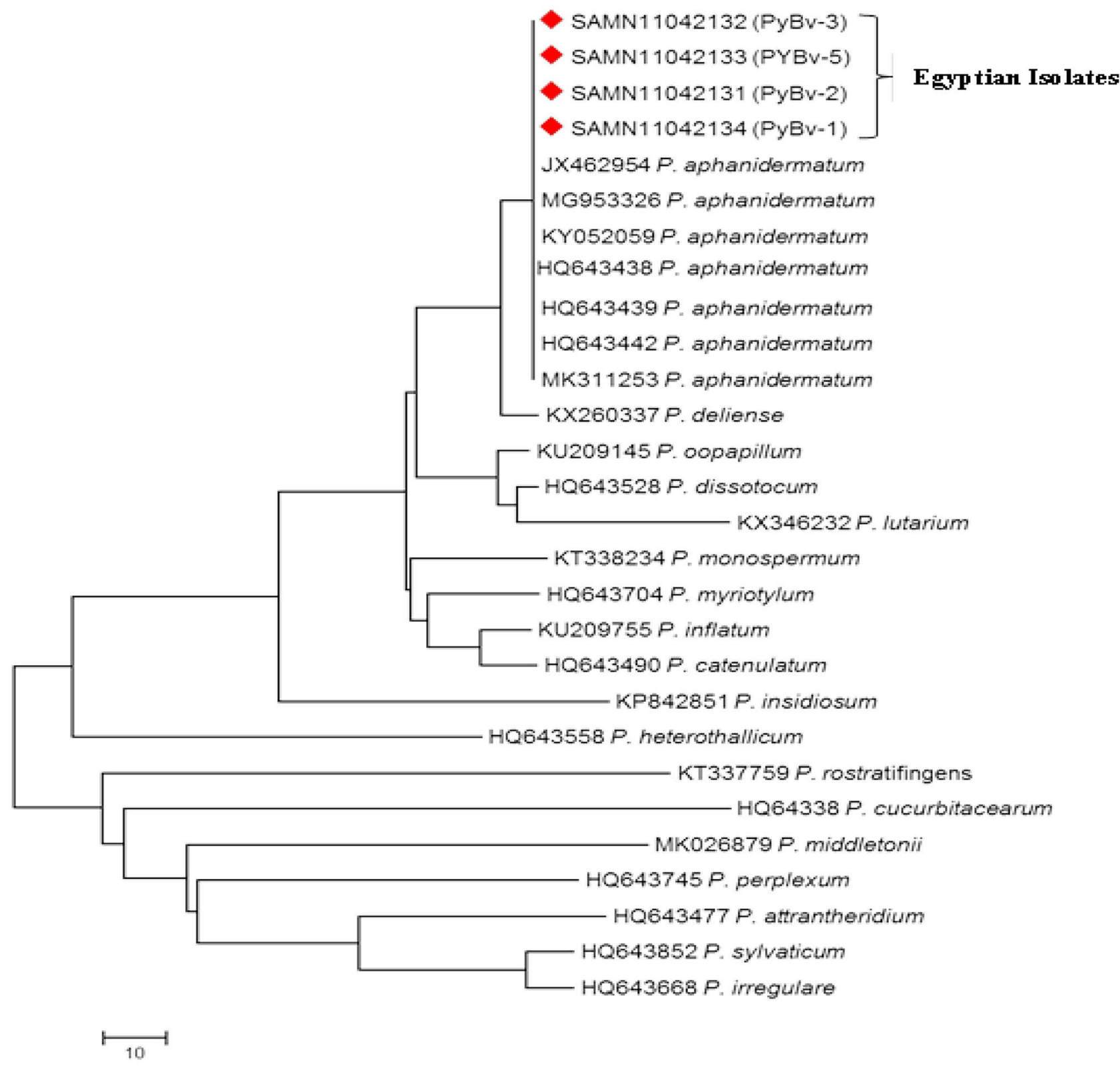

Fig. 2 Phylogenetic tree derived from the internal transcribed spacer (ITS) region sequences of $P$. aphanidermatum and other Pythium spp. isolates using the Neighborhood-Joining method. The percentage of replicate trees in which the associated taxa clustered together

photoperiod. The potting mix was watered three times a week to maintain high moisture levels.

The first symptoms were observed within 7 days after inoculation, when $50 \%$ of the seedlings were wilted and dead, while control plants remained healthy. Stand counts taken at emergence then every 3 to 4 days revealed that all of the inoculated plants had wilted and died 21 days after sowing. Each experiment was conducted twice for reproducibility. The pathogen was re-isolated from dying sugar beet seedlings and confirmed as $P$. aphanidermatum by in the bootstrap test (1000 replicates) are shown next to the branches. GenBank accession numbers for sequences are written left beside the Pythium sp. Phylogenetic analyses were conducted in MEGA6

comparing the morphology of these isolates with the original isolates that were used for inoculation.

To the knowledge of the authors, this is the first report of sugar beet damping-off caused by $P$. aphanidermatum in Egypt. Sugar beet is an economically important crop in the Kafrelsheikh Governorate of Egypt, with growers and farm workers relying on the success of the crop for their livelihood. Future outbreaks of damping off in this crop, particularly if those outbreaks are more widespread, threaten the viability of the industry. Although our findings provide 
information on the cause of the damping-off of sugar beet seedlings, more research is needed to investigate possible control measures. These include rotations with grass and grain crops and improved drainage as well as encouraging growers to use fungicide seed treatments, such as metalaxyl, which are effective against Pythium spp.

Acknowledgements The authors extend their appreciation to all members of Plant Pathology and Biotechnology Laboratory (PPBL) and EPCRS Excellence Centre (accredited according to ISO/17025, 9001, 14001, and OHSAS/18001), Department of Agricultural Botany, Faculty of Agriculture, Kafrelsheikh University, Kafrelsheikh, Egypt.

\section{References}

Brantner JR, Windels CE (1998) Variability in sensitivity to metalaxyl in vitro, pathogenicity, and control of Pythium spp. on sugar beet. Plant Dis 82:896-899
Guo LD, Hyde KD, Liew ECY (2000) Identification of endophytic fungi from Livistona chinensis based on morphology and rDNA sequences. New Phytol 147:617-630

Muthukumar A (2010) Taxonomic studies on four species of the genus Pythium. J Mycol Plant Pathol 40:586-589

Van der Plaats-Niterink AJ (1981) Monograph of the genus Pythium. Stud Mycol 21:1-24

Gherbawy YAMH, Abdelzaher HMA, Meens J, El-Hariry H (2005) Morphological and molecular identification of some closely related Pythium species in Egypt. Arch Phytopathol Plant Prot 38:193-208 